\title{
Investigation on the validity of creep damage mechanics for the life time prediction of T92 welded joint
}

\author{
Xiao Wang', Xue Wang' (1), Qiang $X^{2}{ }^{2}$, Chuang Wang', \\ Ya-lin Zhang ${ }^{3}$ and De-ming Xiao ${ }^{3}$
}

\begin{abstract}
This paper reports the damage evolution in ASME T92 welded joints during creep process. The creep test was conducted at $650^{\circ} \mathrm{C}$ with applied stress of $90 \mathrm{MPa}$. The creep specimen was ultimately fractured at the fine-grained heat affected zones after creep for $1560 \mathrm{~h}$. The metallographic results show that the cavity number and size in fine-grained heat affected zones increase with the creep time. The coalescence of creep cavities happened at the late stage of the creep life, which depending on the adjacent voids grows and propagates into the micro-crack. Besides, the deterioration in fine-grained heat affected zones of T92 steel welded joint with various creep time can be simulated based on the continuum damage mechanics with modified Karchanov-Rabotnov constitutive equation. The result of simulated creep rupture life is in good agreement with the experimental value, which indicates that the continuum damage mech-anics can be used to predict creep life and evaluate creep deterioration in a T92 steel welded joint.
\end{abstract}

\section{Keywords}

T92 steel welded joint, creep damage, evolution process, life prediction, continuum damage mechanics

\section{Introduction}

Conventional supercritical (SC) boilers in electric power plants have the low thermal efficiency, which could produce high $\mathrm{CO}_{2}$ emission and cause global warming. In order to improve the thermal efficiency and reduce the carbon emission, many countries are developing high-capacity ultrasupercritical (USC) power plants with high steam temperature. By increasing the steam temperature

\footnotetext{
'School of Power and Mechanical Engineering, Wuhan University, Wuhan, China

${ }^{2}$ School of Computing and Engineering, The University of Huddersfield, Huddersfield, UK

${ }^{3}$ Guodian Science and Technology Research Institute, Beijing, China

Corresponding author:

Xue Wang, Wuhan University, Room A409, Building No. 8, Hunan Road, Wuhan 430072, China.

Email: wangxue20II@whu.edu.cn
} 
and pressure entering into the turbines, the efficiency can be largely enhanced. Compared with SC boilers, the USC boilers can lead to both an increase of $4-10 \%$ in thermal efficiency and a reduction of $18-22 \%$ in $\mathrm{CO}_{2}$ emission. In the meantime, those materials possessing higher creep property and oxidation resistance are urgently needed to adapt to such kind of severe service conditions (Chen et al., 2012; Gong et al., 2011; Liu et al., 2015).

$9 \% \mathrm{Cr}$ heat resistant steels are the critical materials for the components of USC boilers, such as steam headers, reheaters, and turbine parts. The modified 9\% Cr steel (ASME T/P91) was developed in the USA by the Oak Ridge National Laboratory in the 1970s. Compared with the former 9Cr1Mo steel (EM12), the creep strength has been significantly improved in the T/P91 by adding the chemical compositions such as $\mathrm{V}$ and $\mathrm{Nb}$. These elements lead to the formation of fine $\mathrm{V}$ and $\mathrm{Nb}$-rich precipitates so as to retard the dislocation movement. Based on the development of T/P91, ASME T/P92 steel has been developed in the 1990s, carried out by the Nippon Steel Corporation of Japan. The addition of $\mathrm{W}$ and Mo elements in T/P92 steel plays an important role of solution strengthening, as a result, at the same conditions of pressure and temperature, the permissible stress of T/P92 has been significantly improved compared with the T/P91 steel (An et al., 2011; Chang et al., 2015; Erten et al., 2017; Li et al., 2009).

Currently, the ASME T/P92 steel $(9 \mathrm{Cr}-1.8 \mathrm{~W}-0.5 \mathrm{Mo}-\mathrm{NbV})$ has been widely used in thermal power plant components, since it has high creep fracture strength, good corrosion resistance, and excellent weldability. Nevertheless, it was also reported that the premature failure frequently occurs at the welding heat affected zone of these steels, due to the type IV cracking often taking place in the fine-grained heat affected zones (FGHAZs). The evolution process of the IV cracking involves the cavity nucleation, growth, and coalescence. Then, the micro-cracks form and progressively propagate into the macrocracks, which cause the intergranular fracture of the welded joint (Francis et al., 2006). Meanwhile, it is worth noting that the formation of the creep cavity expends most of the whole creep life, and once the main crack forms, the crack propagates rapidly and fractures immediately. Thus, the IV cracking shortened the creep lifetime of welded joints, which has become a worldwide problem to solve.

In order to prevent this sort of unexpected incidents, it is necessary to investigate the creep damage evolution in T/P92 joint and develop the life prediction technology. In recent years, continuum damage mechanics (CDM) has seen great development (Pandey et al., 2019; Sun et al., 2017; Voyiadjis and Kattan, 2014), which was frequently used for the life prediction of elevated temperature parts by introducing proper damage variables. The advantage of CDM is that it could simulate the damage process and compute the stress and strain state of a material element. In this research, a multi-axial creep damage model ( $\mathrm{K}-\mathrm{R}$ equation) was used to describe the creep damage in T92 welded joint. In addition, a comparison between the simulation results and experimental results was carried out to verify the effectiveness of this prediction method.

\section{Experimental work}

\section{Material specification}

The chemical composition of the ASME T92 steel was as follows (in mass \%): $0.10 \mathrm{C}, 0.37 \mathrm{Mn}, 0.35 \mathrm{Si}$, $0.18 \mathrm{Ni}, 0.38 \mathrm{Mo}, 1.58 \mathrm{~W}, 0.21 \mathrm{~V}, 0.05 \mathrm{Nb}, 0.03 \mathrm{Co}, 0.06 \mathrm{Cu}, 0.04 \mathrm{~N}$. The welded joints of T92 tube $(\mathrm{D} 45 \times 10.8 \mathrm{~mm})$ were prepared by means of gas tungsten arc welding (GTAW). The used weld filler wires were as follows (in mass $\%$ ): $0.08 \mathrm{C}, 0.78 \mathrm{Mn}, 0.30 \mathrm{Si}, 0.52 \mathrm{Ni}, 0.29 \mathrm{Mo}, 1.52 \mathrm{~W}, 0.20 \mathrm{~V}$, $0.03 \mathrm{Nb}, 0.91 \mathrm{Co}, 0.06 \mathrm{~N}$. The procedure conditions of GTAW are given in Table 1 .

Postweld heat treatment was carried out at $760^{\circ} \mathrm{C}$ for $90 \mathrm{~min}$, and then cooled in air. At last, the creep specimens were machined out from these welded joints, and the weld metal (WM) was located 
Table I. The procedure conditions of GTAW.

\begin{tabular}{ll}
\hline Parameter & Value/description \\
\hline Filler wire diameter & $2.4 \mathrm{~mm}$ \\
Weld preparation & $\mathrm{V}$ groove \\
Preheating temperature & $150-250^{\circ} \mathrm{C}$ \\
Welding current & $100-120 \mathrm{~A}$ \\
Arc voltage & $11-14 \mathrm{~V}$ \\
Welding speed & $40-70 \mathrm{~mm} \mathrm{~min}^{-1}$ \\
Multi-layer & 4 layers and 8 passes
\end{tabular}

GTAW: gas tungsten arc welding.

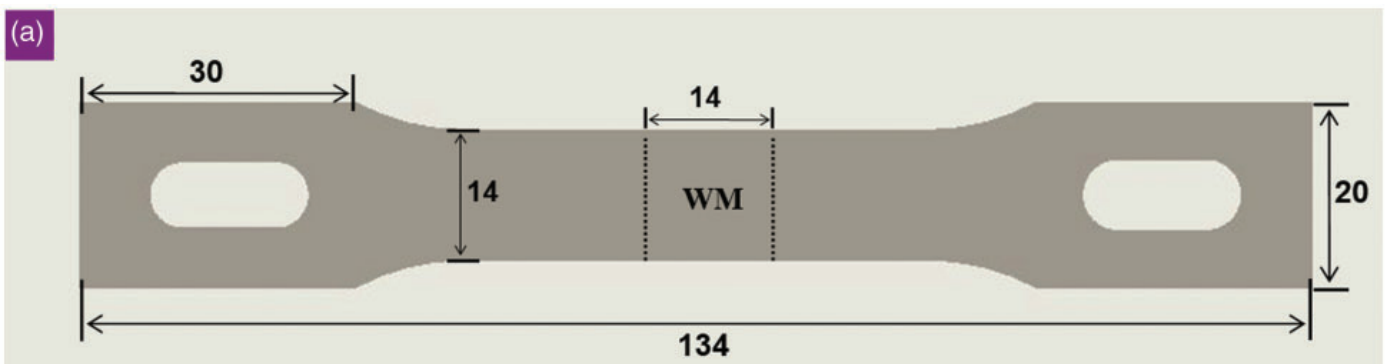

(b)

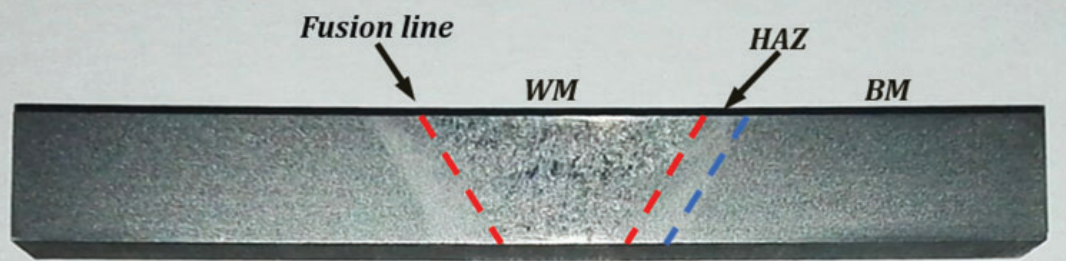

\section{$1 \mathrm{~cm}$}

Figure I. The schematic diagram of the T92 welded joint. (a) Creep specimen of this welded joint (all dimensions in millimeters) and (b) longitudinal section of this welded joint. BM: base metal; HAZ: heat affected zone; WM: weld metal.

in the center of specimen gauge length (see Figure 1(a)). The thickness of this creep specimen was $8.5 \mathrm{~mm}$. The width of HAZ is nearly $2.2 \mathrm{~mm}$, which includes the CGHAZ and FGHAZ; besides, the weld groove is about $32^{\circ}$, which can be recognized in Figure 1(b).

\section{Test procedure}

First, creep rupture test was performed at $650^{\circ} \mathrm{C}$ with a constant load of $90 \mathrm{MPa}$. After $1560 \mathrm{~h}$, the T92 welded joint fractured, and the fracture location is about $2 \mathrm{~mm}$ away from the fusion line, 

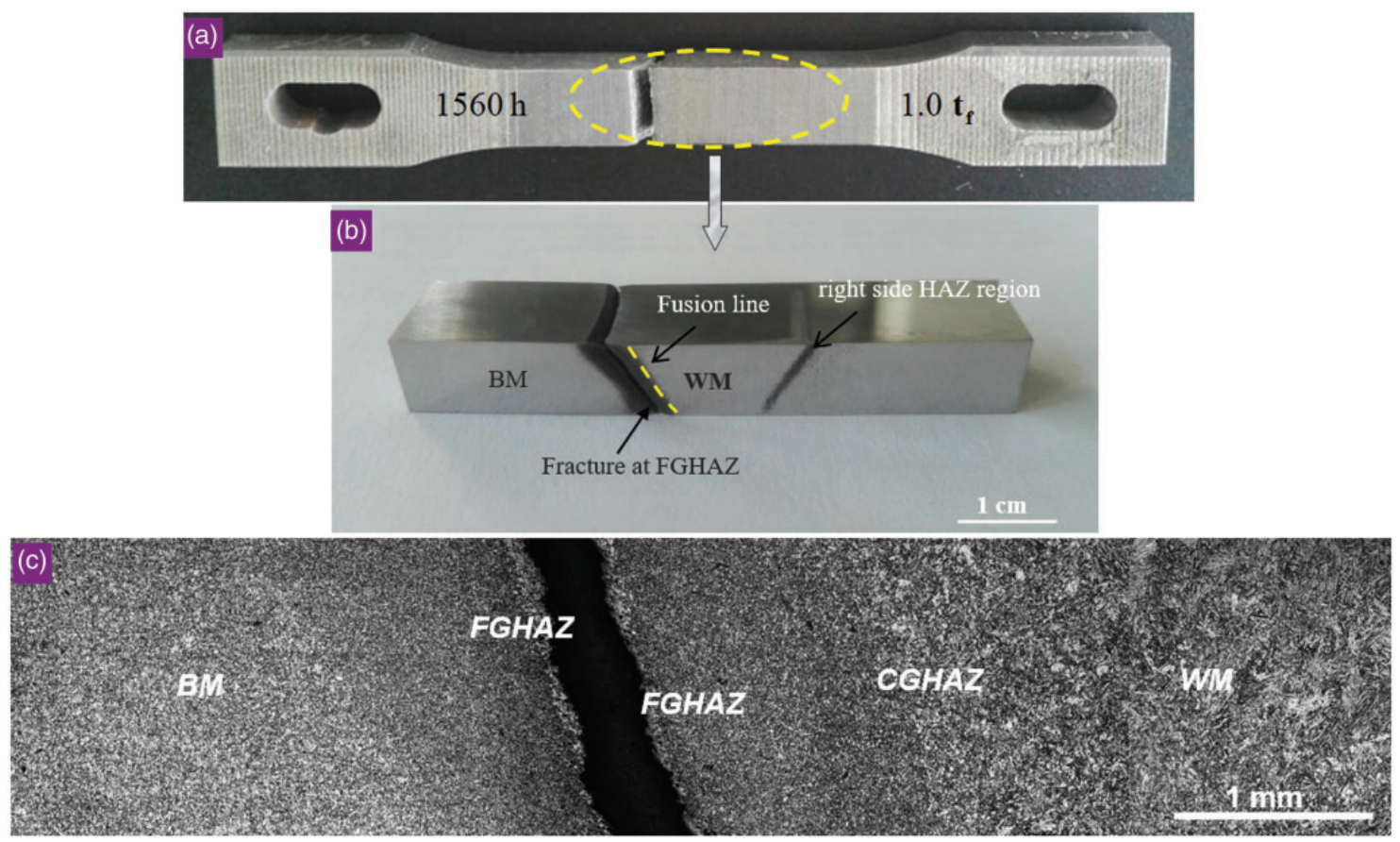

Figure 2. Schematic diagrams of macro-microstructure of the fracture T92 welded joint. BM: base metal; CGHAZ: course-grained heat affected zone; FGHAZ: fine-grained heat affected zone; WM: weld metal.

which indicates that the premature failure of the T92 welded joint preferentially takes place in the FGHAZ (see Figure 2). Then, creep interrupted tests were carried out at designated time (i.e. $312 \mathrm{~h}$ $\left.\left(20 \% \mathrm{t}_{\mathrm{f}}\right), 624 \mathrm{~h}\left(40 \% \mathrm{t}_{\mathrm{f}}\right), 936 \mathrm{~h}\left(60 \% \mathrm{t}_{\mathrm{f}}\right), 1248 \mathrm{~h}\left(80 \% \mathrm{t}_{\mathrm{f}}\right)\right)$ in order to study the creep damage evolution in FGHAZ. After the creep exposures, the T92 specimens were cut into small pieces for metallographic observation. Detailed investigation of the microstructure by means of SEM (ZEISSEVO18) was conducted. Since the breakage happened at the left side of fracture T92 joint, the right side of specimens was uniformly selected for investigation. Besides, the micro-hardness of joints was measured using an indentation load of $100 \mathrm{~g}\left(\mathrm{HV}_{0.10}\right)$.

\section{Results and discussion}

\section{Original microstructures of the ASME T92 welded joint}

The SEM images of each region of the original T92 steel welded joint are shown in Figure 3. This joint is composed of four regions, which include the WM, coarse-grained heat affected zone (CGHAZ), FGHAZ, and base metal (BM). It was reported that the distribution of peak temperature in T92 joint was various during the welding, therefore, the formed microstructures are different after subsequent cooling. Since the region of FGHAZ is away from the fusion line, and the carbides cannot be completely dissolution. Thus, the austenitizing transition fulfills partially, which results in the formation of FGHAZ (Abe, 2004).

In the initial state, the microstructures of WM, BM, and CGHAZ have typical tempered martensitic structure, and the WM also has coarser grain that was formed during the rapid solidification 

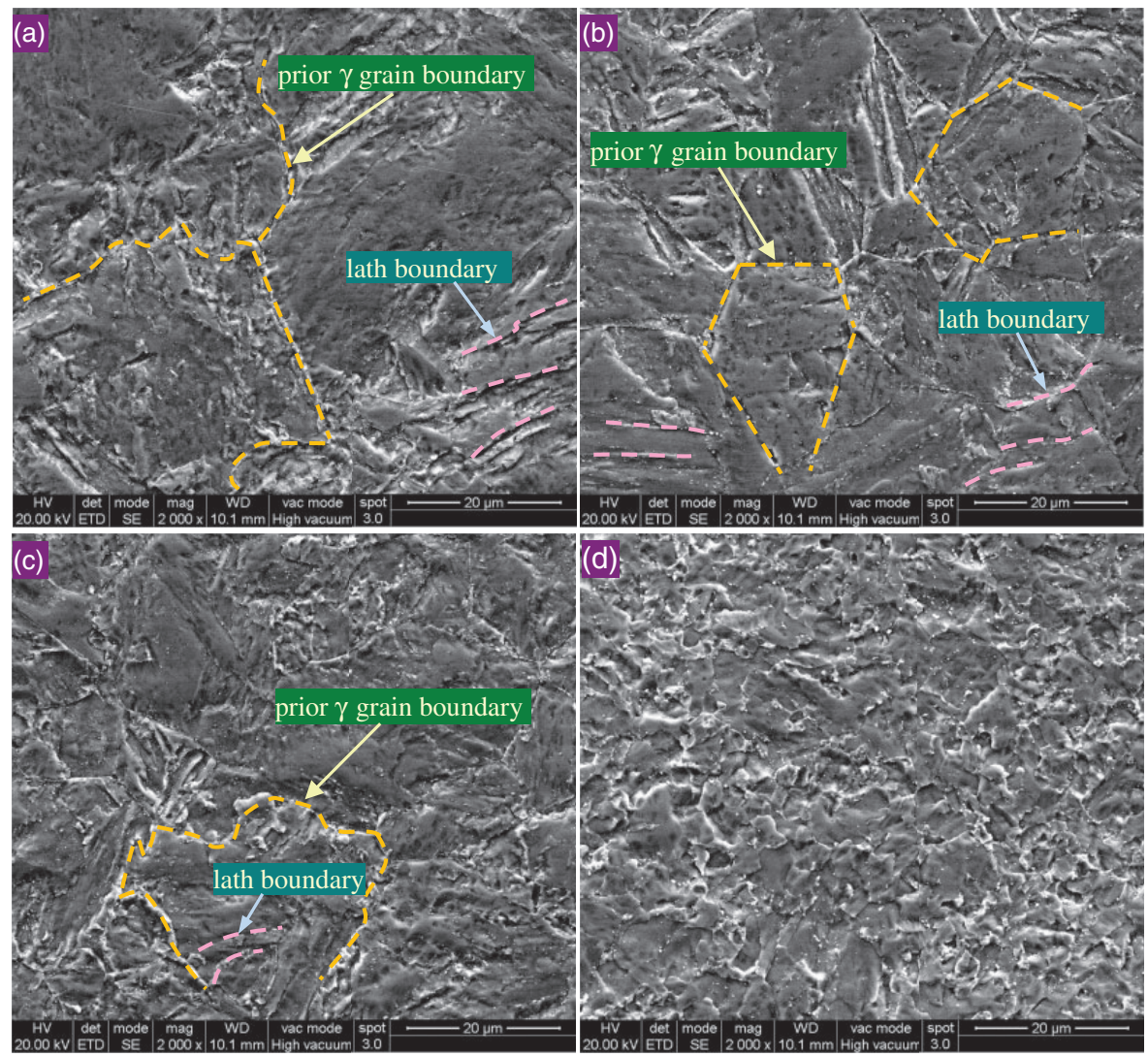

Figure 3. SEM images of each part of the original T92 welded joint. (a) WM, (b) BM, (c) CGHAZ, and (d) FGHAZ.

(see Figure 3(a)). Besides, the structural feature of martensite lath boundary and prior $\gamma$ grain boundary can be clearly recognized in these regions, which were marked with the dashed line in Figure 3. Meanwhile, the microstructure of FGHAZ was the tempered martensitic (Wang et al., 2017), and the grain size of this region is much smaller than that of the other regions. Previous researches (Matsui et al., 2001; Wang et al., 2017) indicated that the lath sub-structure of martensite is a key factor to achieve the strengthening in T92 steel, due to it containing a mass of sub-grain boundaries and high dislocation density. However, the microstructure of FGHAZ is absence of martensitic laths, thus, FGHAZ is a softening region, which has lower creep resistant ability compared with the other regions.

\section{Microstructures of the ASME T92 welded joint after creep fracture}

The SEM image of the fractured T92 steel joint is shown in Figure 4; after the joint rupture, the microstructures of WM and BM still maintained a stable lath structure, and no creep cavity was observed in these two zones (see Figure 4(a) and (b)). However, there are a large number of creep cavities present in the FGHAZ, which confirms that FGHAZ is the most serious damage region of the T92 welds. Besides, previous investigations (Goods and Brown, 1979; Shinozaki and Kuroki, 2003; Van Zyl, 2005) have shown that the growing up and coalescence of creep void 

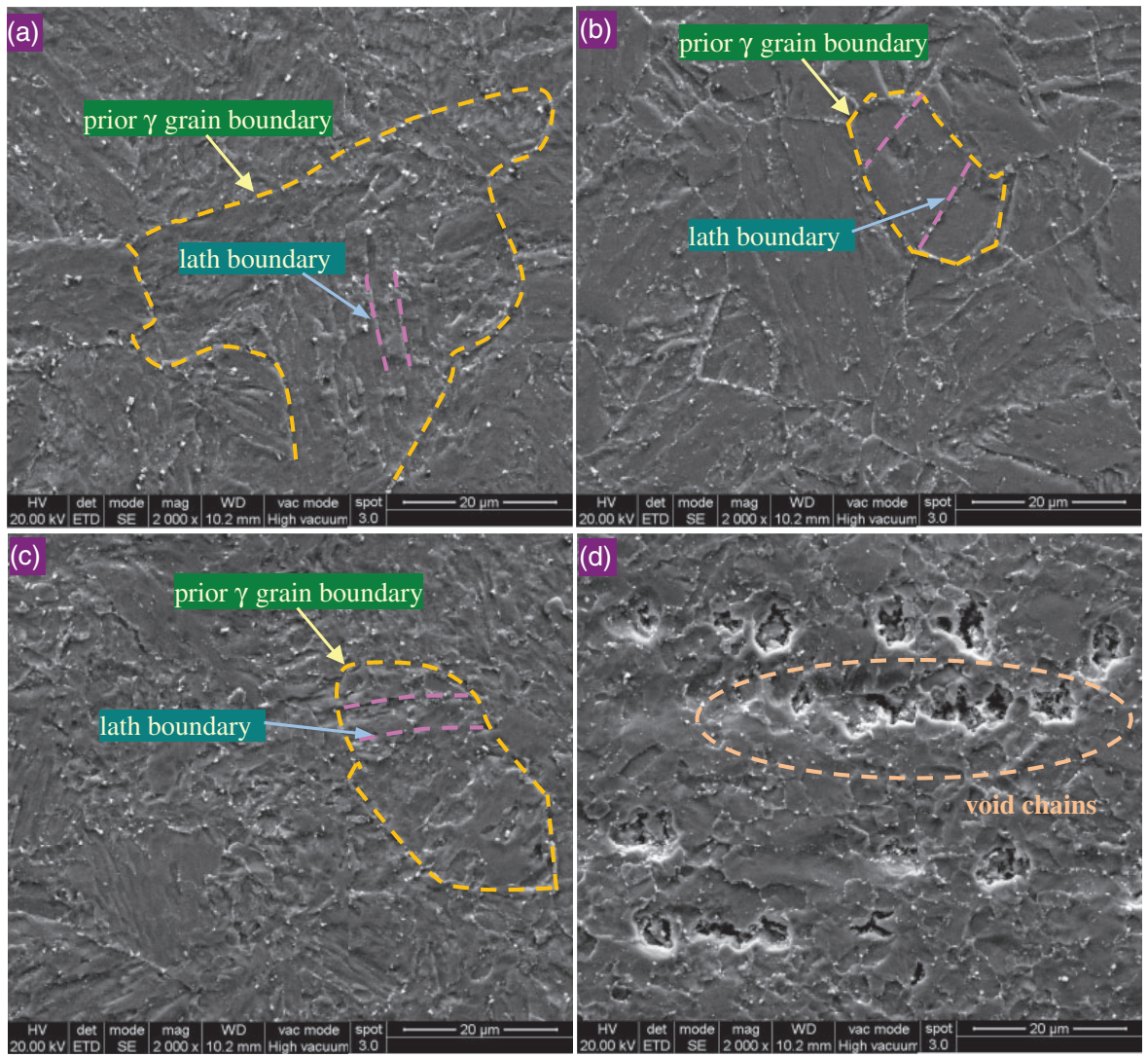

Figure 4. SEM images of each part of the fracture T92 steel welded joint. (a) WM, (b) BM, (c) CGHAZ, and (d) FGHAZ.

have continued up to the very late stage of the creep life, once the micro-cracks initiation and propagation, the T92 welded joint will break up in a very short period of time. As shown in Figure 4(d), in the right side of HAZ region, the void's coalescence could be found in FGHAZ of the $1.0 \mathrm{t}_{\mathrm{f}}$ specimen, which forebode that the cavity chains will propagate into the micro-cracks, and finally form the macroscopic type IV cracking to cause the joint failure.

The hardness profile across the T92 welded joint before and after creep fracture is shown in Figure 5. Before creep, the WM region possesses a large hardness of about $240 \mathrm{HV}$. Meanwhile, the hardness progressively decreases with increasing distance from the fusion line, and the lowest hardness value of this joint appeared in the FGHAZ region, which is only $181 \mathrm{HV}$. After creep fracture experiment, by comparison with the original T92 joint, the hardness of WM in the fractured specimen does not change very much, but the hardness of HAZ decreased significantly, which revealed that the FGHAZ is a softening zone.

\section{The evolution of creep damage of the ASME T92 welded joint}

To investigate the evolution process of creep damage, the metallographic examination of FGHAZ of T92 welded joints was observed at the specimens with different life fraction. The SEM images of a 


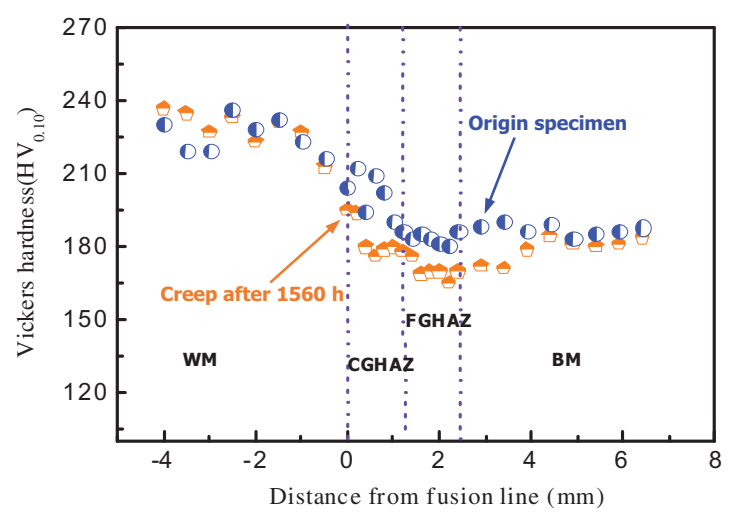

Figure 5. Hardness profile across the specimen before and after the creep fracture test. BM: base metal; CGHAZ: course-grained heat affected zone; FGHAZ: fine-grained heat affected zone; WM: weld metal.

representative overview of FGHAZ are shown in Figure 6. The progress of the cavity evolution with increasing creep time can be clearly recognized. The results were summarized as follows: (1) within the $20 \% \mathrm{t}_{\mathrm{f}}$, there was hardly any creep cavity that can be observed; (2) when the life fraction increase to $40 \%$, the creep cavities can be detected, with a relatively small size; (3) after creep for $936 \mathrm{~h}$ $\left(60 \% \mathrm{t}_{\mathrm{f}}\right)$, the number of the creep cavities increases rapidly, which were widely distributed near the grain boundaries; (4) after creep for $1560 \mathrm{~h}$, it can be observed that, in the $1.0 \mathrm{t}_{\mathrm{f}} \mathrm{T} 92$ specimen, the cavity number and size increased simultaneously in the FGHAZ, which indicates that the creep damage is serious at the later stage. At last, the adjacent cavities join together and propagate into the type IV cracking, which cause the joint fracture. In addition, the cavity number density and size distribution in FGHAZ are shown in Figure 7.

\section{Numerical simulation of the creep damage of the T92 welded joint}

It was once thought that the Norton creep equation could be used to describe the stresses and strains occurring in primary and secondary creep stages. However, for the life of materials controlled by fracture, it is necessary to analyze their creep behavior in the tertiary region. As a new branch of solid mechanics, CDM has seen great improvement in recent years. CDM provides a better understanding of rupture mechanics by using damage variables, which could determinate the deterioration of a material element (Yao et al., 2007).

Based on the physical nature of the damage, the damage of metal material may be interpreted as the creation of micro surfaces of discontinuities at the micro scale (voids, micro-cracks, etc.), which induces a loss of effective cross-sectional area that carries the load. Though the basic idea is due to Kachanov (Xiao, 2004; Ż yezkowski, 2000), 1958. Kachanov introduced a continuous scalar field variable and called it "continuity"

$$
=A_{\text {net }} / A_{0}
$$

where $A_{0}$ is the initial cross-sectional area and $A_{\text {net }}$ is the effective cross-sectional area which effectively bears the load. Odqvist and Hult (Hayhurst at., 2005), introduced a more 

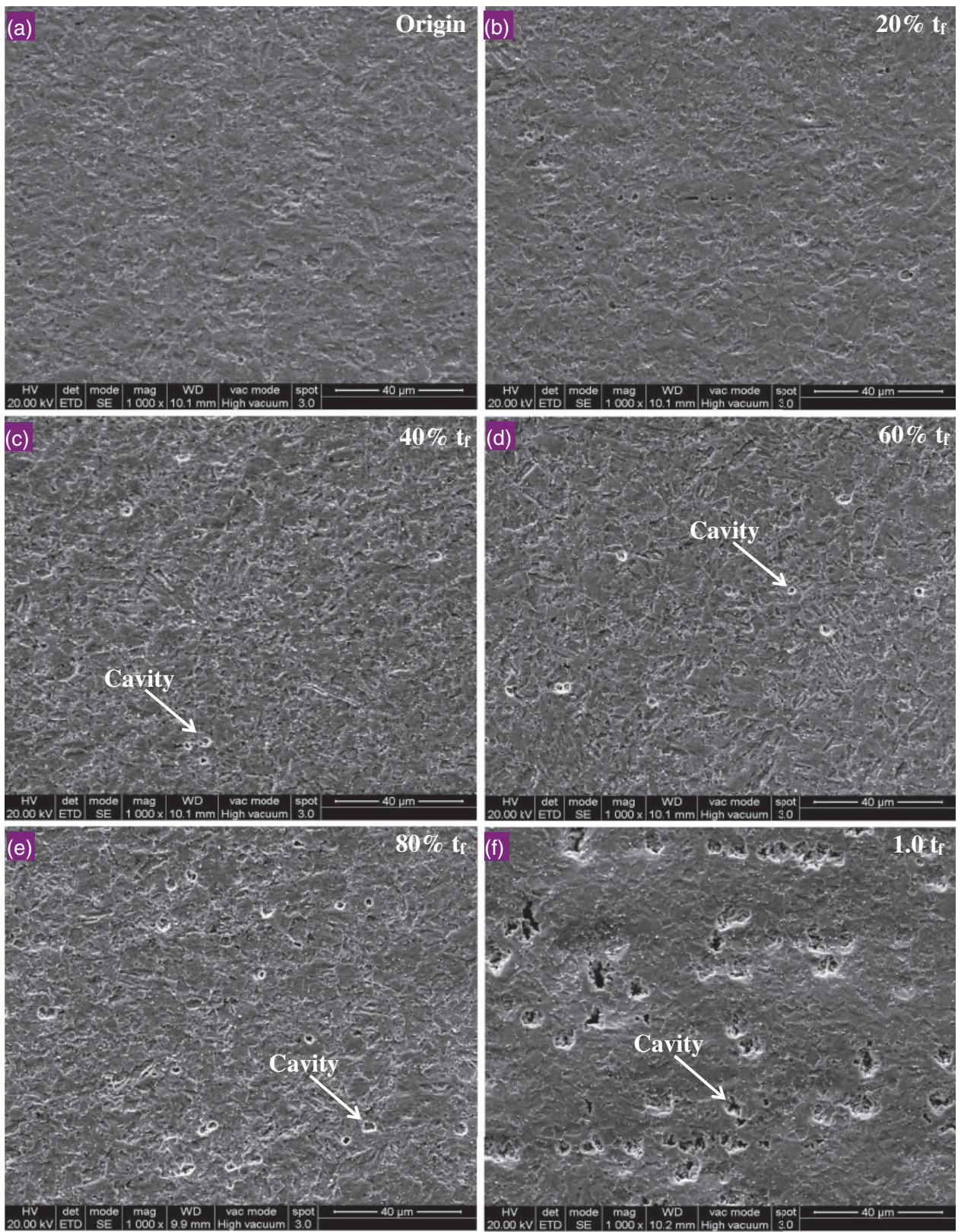

Figure 6. Creep cavities in FGHAZ of the T92 welds at different life fractions.

convenient variable $D$

$$
D=1-\psi=\frac{A_{0}-A_{n e t}}{A_{0}}
$$



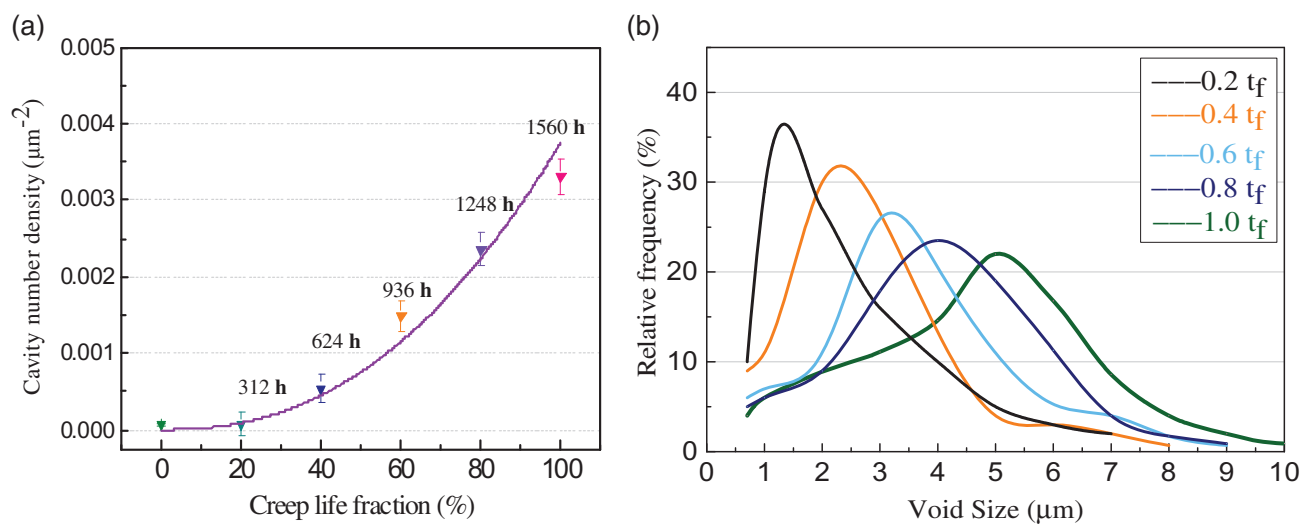

Figure 7. The cavity density and size distribution in FGHAZ of the T92 joint.

And call it "damage variable," it starts from $D=0$ ending with $D=1$. Further, the concept of effective stress was introduced to describe the effect of damage on strain behavior. Stress $\tilde{\sigma}$ is written as the mean density of tensile forces $P$ acting on the effective cross-section

$$
\tilde{\sigma}=\frac{P}{A_{\text {net }}}=\frac{\sigma}{1-D}
$$

Lamaitre (Xia 2004$)$ gave another interpretation of effective stress $\tilde{\sigma}$ by introducing the concept of equivalence strain. The strain associated with a damaged state under applied stress is equivalent to the strain associated with an undamaged state under effective stress. Then, Hook's law of a damaged material in the one-dimensional case can be written as

$$
\varepsilon=\frac{\sigma}{E}=\frac{\sigma}{E(1-D)}
$$

where $\varepsilon$ is the elastic strain and $E$ is the young's modulus of undamaged material. To reflect the deterioration of materials and describe the tertiary creep stage, Kachanov (Yaeet al., 2007), proposed a phenomenological method. For uniaxial tension, he suggested the constitutive equations

$$
\dot{\varepsilon}_{c}=\frac{K \sigma^{n}}{(1-D)^{m}}, \quad D=\frac{A \sigma^{p}}{(1-D)^{q}}
$$

This is the so-called classical Kachanov-Robotnov equations, $\dot{\varepsilon}_{c}$ is the creep strain state, and the $K, A, n, m, p, q$ are time and temperature-dependent material constants and can be determined from uniaxial creep tension tests. Integrating the equation set under the conditions of $D=0$ when $t=0$ and $D=1$ when $t=t_{\mathrm{r}}$, the rupture time and creep strain are obtained by

$$
t_{\mathrm{r}}=\frac{1}{(1+q) A \sigma^{p}}, \quad \varepsilon_{c}=\lambda \dot{\varepsilon}_{0} t_{\mathrm{r}}\left[1-\left(1-\frac{t}{t_{\mathrm{r}}}\right)^{1 / \lambda}\right]
$$


where $\lambda=p+1 / p+1-q, \dot{\varepsilon_{0}}=K \sigma^{n}$. Beside, the creep rupture strain can be written as

$$
\varepsilon_{\mathrm{r}}=\lambda \dot{\varepsilon}_{0} t_{\mathrm{r}}
$$

For the components subjected to the complicated stress states, it is essential to generalize the creep damage constitutive equations from uniaxial stress conditions to multi-axial stress (Hongo et al., 2013; Hyde et al., 2006; Perrin and Hayhurst, 1996; Zhao et al., 2012). Typically, the multiaxial creep Kachanov-Robotnov equations can be expressed as

$$
\begin{aligned}
\frac{d \varepsilon_{i j}^{c}}{d t} & =\frac{3}{2} A^{\prime}(\bar{\sigma})^{n-1} S_{i j}\left[(1-\rho)+\rho(1-D)^{-n}\right], \\
\frac{d D}{d t} & =g \frac{B}{\phi+1} \frac{\left[\alpha \sigma_{1}+(1-\alpha) \bar{\sigma}\right]^{v}}{(1-D)^{\phi}} \\
D_{\mathrm{cr}} & =1-(1-g)^{1 /(1+\phi)}
\end{aligned}
$$

where $\varepsilon_{i j}^{c}$ is the creep strain tensor, $\bar{\sigma}$ is the von Mises equivalent stress, $\sigma_{1}$ is the maximal principal stress, $S_{i j}$ is the deviatoric stress tensor, $D$ is the damage variable, $D_{\mathrm{cr}}$ is the critical damage, and $D /$ $D_{\text {cr }}$ is the damage factor. When $D / D_{\text {cr }}=1$ means that the material is damaged completely. $\alpha$ is the multiaxial stress parameter $(0<\alpha<1), \phi, g$, and $\rho$ are material constants accounting for the inhomogeneity of the damage, where $\rho$ represents the volumetric ratio of the damage phase. $A^{\prime}, B, v$, and $n$ are the material constants related to the minimum creep strain rate and rupture behavior, which can be described as follows

$$
\dot{\varepsilon}_{\min }^{c}=A^{\prime} \sigma^{n}, \quad t_{f}=\frac{1}{B \sigma^{v}}
$$

where $\dot{\varepsilon}_{\min }^{c}$ is the minimum creep strain rate, $t_{f}$ is the rupture time, and $\sigma$ is the applied stress under the uniaxial creep test.

In this letter, the user defined material subroutine (UMAT) is compiled based on modified Karchanov-Rabotnov constitutive equation. The creep damage accumulation in a welded joint of ASME T92 steel at $650^{\circ} \mathrm{C}$ and $90 \mathrm{MPa}$ was calculated by ABAQUS with subroutine. The material properties of different zones are listed in Table 2 (Zhao et al., 2012).

We establish a two-dimensional model containing four zones (i.e. WM, CGHAZ, FGHAZ, and $\mathrm{BM}$ ). The model size is simplified from the experimental creep specimen, which are $20 \mathrm{~mm}$ long $\times 8.5$ $\mathrm{mm}$ wide with a WM width of $7 \mathrm{~mm}$, and a HAZ width of $2.2 \mathrm{~mm}$ (the FGHAZ width is $1 \mathrm{~mm}$, the CGHAZ width is $1.2 \mathrm{~mm}_{\mathrm{A}}$ (see Figure 8). The model is fixed at the left side, and a uniform tensile stress of $90 \mathrm{MPa}$ is applied at the right side. It should be noted that the variation in material properties in real welded joints is continuous; however, in order to reduce model complexity, the welded joint was considered to consist of WM, CGHAZ, FGHAZ, and BM, individually.

Figure 9 represents the creep damage contours in this welded joint with various creep times. Compared with the other zones in this joint, the FGHAZ reveals a significantly higher degree of damage in the creep process, which manifest that the FGHAZ is the weakest part of the welded joint. Besides, the results of simulation show that the damage factor $\left(D / D_{\mathrm{cr}}\right)$ of most elements in FGHAZ reaches to 1 in the $1.0 \mathrm{t}_{\mathrm{f}}$ specimen, which means that the welded joint is completely 
Table 2. Material properties for the welded joints of ASME T92 steel at $650^{\circ} \mathrm{C}$.

\begin{tabular}{lllllllll}
\hline Constants & $A^{\prime}$ & $n$ & $g$ & $\phi$ & $\alpha$ & $B$ & $v$ & $\rho$ \\
\hline Welded metal & $6.70 \mathrm{E}-040 \mathrm{E}-040$ & 16.4518 & 0.966615 & 7.20317 & 0.43 & $1.22 \mathrm{E}-035$ & 15.1317 & 0.0471326 \\
CGHAZ & $1.154 \mathrm{E}-040$ & 16.4476 & 0.998283 & $12.248 \mathrm{I}$ & 0.43 & $3.73 \mathrm{E}-032$ & $13.27 \mathrm{I}$ & 0.126224 \\
FGHAZ & $5.969 \mathrm{E}-040$ & 16.98356 & 0.95668 & 7.31333 & 0.43 & $5.75 \mathrm{E}-040$ & 18.8176 & 0.076309 \\
Base metal & $1.059 \mathrm{E}-038$ & 15.746 & $0.99521 \mathrm{I}$ & 11.0108 & 0.43 & $2.657 \mathrm{E}-037$ & 15.7096 & 0.099287 \\
\hline
\end{tabular}

CGHAZ: course-grained heat affected zone; FGHAZ: fine-grained heat affected zone.

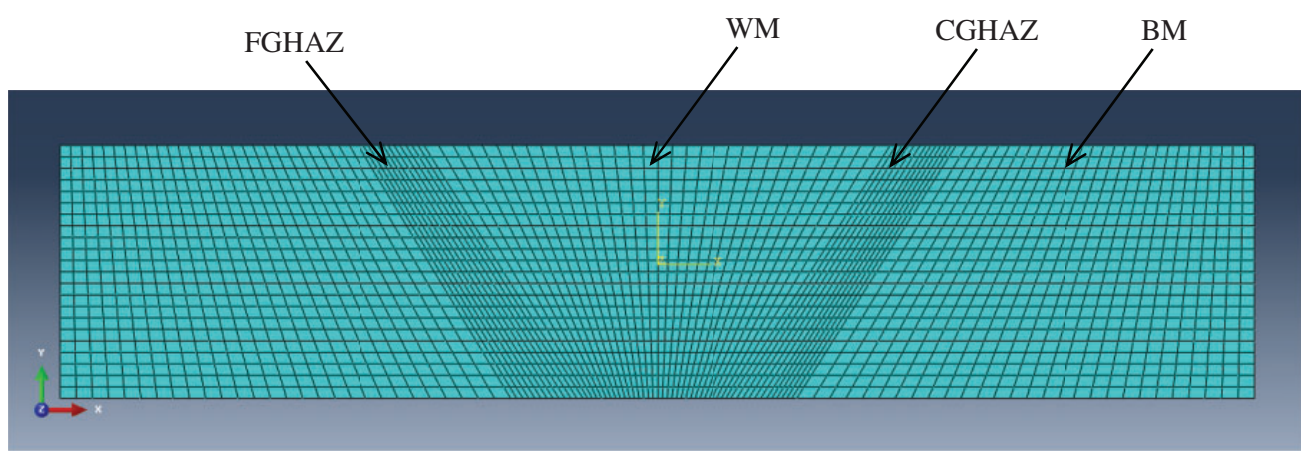

Figure 8. The finite element model of T92 welded joint. BM: base metal; CGHAZ: course-grained heat affected zone; FGHAZ: fine-grained heat affected zone; WM: weld metal.

damaged after creep for $1560 \mathrm{~h}$. Meanwhile, compared with the experiment result in Figure 2, it can be seen that after creep for $1560 \mathrm{~h}$, the welded joint fractured on the one side of the FGHAZ, which verified the effectiveness and availability of this numerical simulation method.

The distributions of the right side of equivalent creep strain, equivalent stress, and maximum principal stress along the centerline of the specimen are evaluated to investigate the creep damage in the welded joint. Figure 10(a) shows the equivalent creep strain in the welded joint after different creep times; it can be seen that the equivalent strain is low in the WM and BM regions away from the HAZ but large in the FGHAZ. Moreover, with the creep time increasing, the equivalent strain of the FGHAZ is accumulated faster than that of other zones in the welded joint, which indicates that the creep damage is accumulated more easily in the FGHAZ, and this may be the main reason for type IV cracking formation in the FGHAZ.

Figure 10(b) shows the equivalent stress in the welded joint after different creep times; it can be identified that, after a long creep time, there is a significant difference of stress distribution in the WM, CGHAZ, FGHAZ, and BM. For the CGHAZ/FGHAZ and FGHAZ/BM interface, the equivalent stress is low in the FGHAZ but high in the CGHAZ and BM regions adjacent to the FGHAZ. This means that if FGHAZ creeps BM and CGHAZ deform less and will impose constraints on the FGHAZ to prevent its creep deformation. The constraint leads to high equivalent stress in the CGHAZ and BM region and causes the stress concentration in CGHAZ/FGHAZ and FGHAZ/BM interface.

Figure 10(c) shows the distribution of maximum principal stress in the welded joint, compared with the WM, CGHAZ, and BM; we could see that the maximum principal stress is higher in the 
(a)

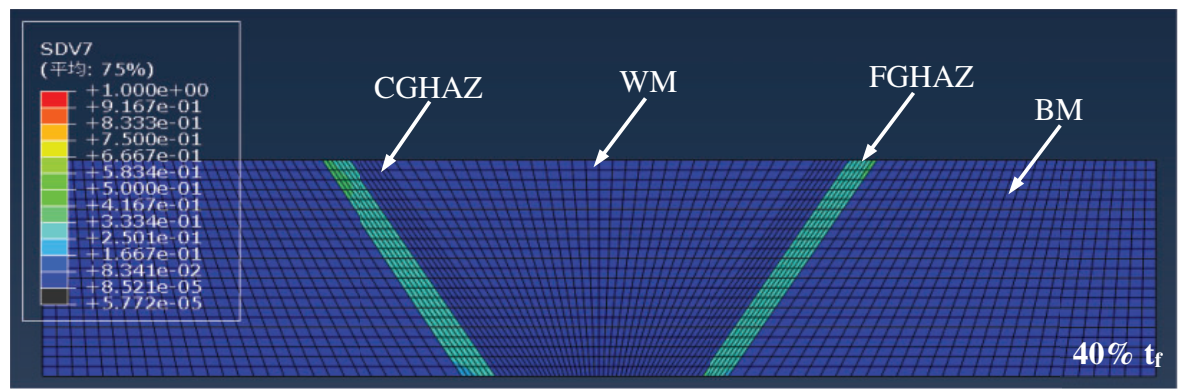

(b)

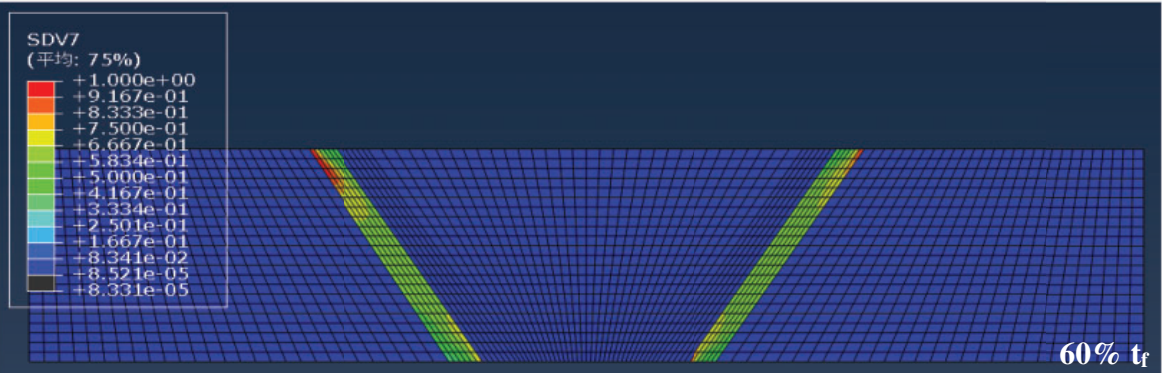

(c)

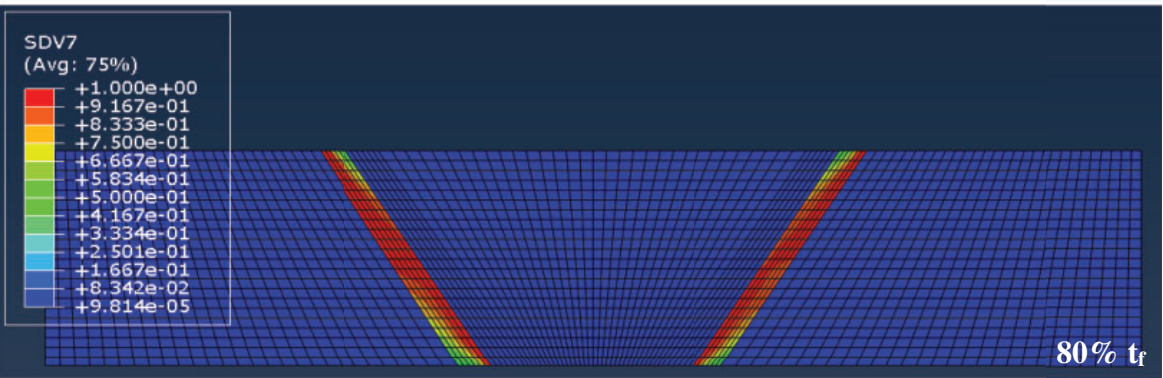

(d)

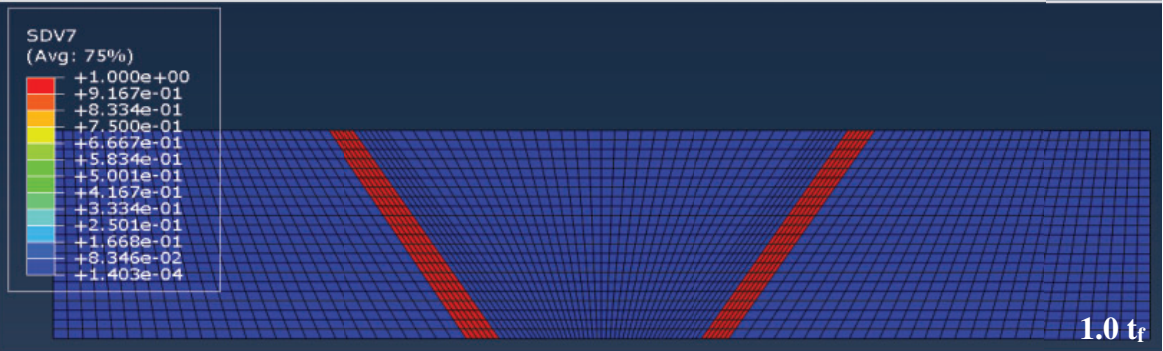

Figure 9. The evolution of creep damage of T92 welded joint crept for different times. BM: base metal; CGHAZ: course-grained heat affected zone; FGHAZ: fine-grained heat affected zone; WM: weld metal.

FGHAZ. Meanwhile, the larger creep damage also occurs in the FGHAZ, which may indicate that the maximum principal stress plays an important role on the accumulation of the creep damage. Shinozaki and Kuroki (2003) suggested that despite the equivalent stress being low in the FGHAZ, the high maximum principal stress also indicates there is a severe stress state in this region. Further, Jablokov et al. (2001) have found that the high maximum principal stress could also accelerate the growth and coalescence of creep voids, which result in the subsequent micro-crack formation during creep. 

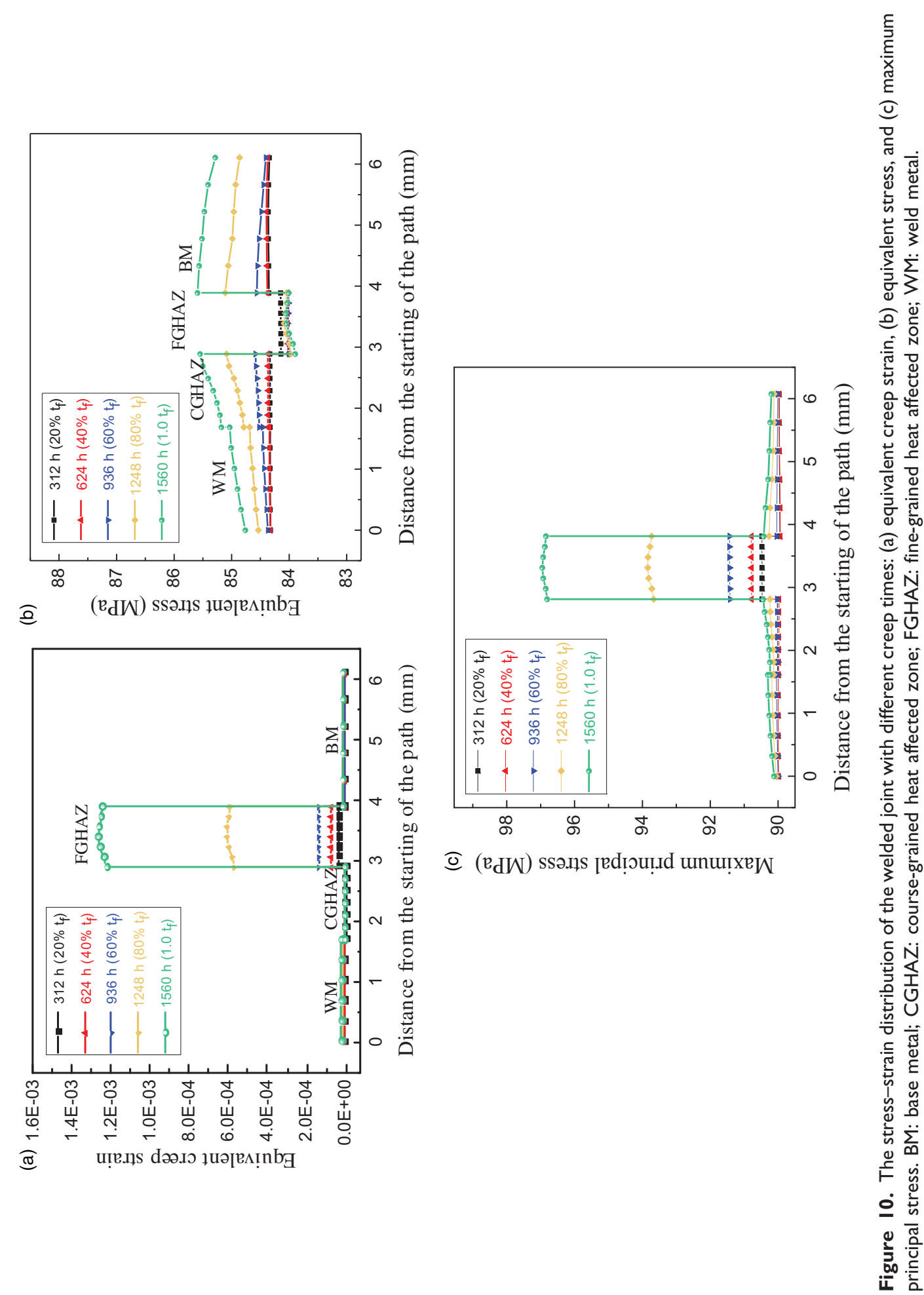
Generally, it is believed that the equivalent creep strain could represent the extent of creep deformation and should be considered to be an important parameter to evaluate the creep damage. Goods and Brown (1979) believed that there exists a critical strain to cause the void nucleation; below this strain the void does not occur; Van Zyl (2005) believed that the creep strain rate is directly proportional to the void formation rate, and further, could be used to predict the creep void occurrence in welded joints. Besides, the process of type IV cracking can be described based on the stress-strain analysis. When stress is applied, stress and strain concentrations occur due to different material properties in the welded joint. The strain concentration in the FGHAZ increases with creep time and the high equivalent strain leads to the occurrence of creep voids. After a long creep time, many creep voids occur, some of which begin to coalesce to form small micro-crack. The maximum principal stress accelerates this process. Finally, the small micro-crack coalesces into macro-crack and type IV cracking occurs in the FGHAZ, which causes the welded joint failure.

\section{Conclusion}

The creep damage evolution process in T92 welded joints was studied in this work. With the increasing of the creep time, the cavity number and size in FGHAZ increased significantly. At last, the coalescence of the adjacent cavities formed into the micro-crack, and finally propagates into the type IV cracking causing joint fracture. The creep deterioration of the T92 welded joint with various creep times was simulated based on the CDM with modified Karchanov-Rabotnov constitutive model. The simulation results show that the damage factor $\left(D / D_{\mathrm{cr}}\right)$ of most elements in FGHAZ reaches to 1 after creep for $1560 \mathrm{~h}$. Meanwhile, the welded joint fractured on the one side of the FGHAZ, which verified the effectiveness of this numerical simulation method. Besides, the distribution of equivalent creep strain in this joint is not uniform. After creep, the equivalent creep strain is higher in FGHAZ than the other regions, which manifests that the FGHAZ is the worst affected areas. On the contrary, the equivalent creep stress is low in the FGHAZ but higher in the other region that is adjacent to the FGHAZ, which causes the stress concentration in CGHAZ/ FGHAZ and FGHAZ/BM interface. In addition, the maximum principal stress is also higher in the FGHAZ, which contributes to the growth and coalescence of cavities during creep.

\section{Declaration of conflicting interests}

The author(s) declared no potential conflicts of interest with respect to the research, authorship, and/or publication of this article.

\section{Funding}

The author(s) disclosed receipt of the following financial support for the research, authorship, and/or publication of this article: The authors would like to express their gratitude for projects supported by the National Natural Science Foundation of China (51374153 and 51574181) and Sichuan Science and Technology Program (2018JY0668).

\section{ORCID iD}

Xue Wang (D) https://orcid.org/0000-0001-8205-9468

\section{References}

Abe F (2004) Coarsening behavior of lath and its effect on creep rates in tempered martensitic 9Cr-W steels. Materials Science \& Engineering A 387(1): 565-569. 
An J, Jing H, Xiao G, et al. (2011) Analysis of the creep behavior of P92 steel welded joint. Journal of Materials Engineering \& Performance 20(8): 1474-1480.

Chang Y, Xu H, Ni Y, et al. (2015) The effect of multiaxial stress state on creep behavior and fracture mechanism of P92 steel. Materials Science \& Engineering A 636: 70-76.

Chen G, Song Y, Wang J, et al. (2012) High-temperature short-term tensile test and creep rupture strength prediction of the T92/TP347H dissimilar steel weld joints. Engineering Failure Analysis 26(12): 220-229.

Erten DT, Nguyen TT, Jeong TM, et al. (2017) Creep deformation and rupture behaviour of service exposed P91 weld and base steel measured by miniature tensile creep testing. Materials at High Temperatures 1-9.

Francis JA, Mazur W and Bhadeshia HKDH (2006) Review type IV cracking in ferritic power plant steels. Materials Science \& Technology 22(12): 1387-1395.

Gong YI, Cao J, Li-Na JI, et al. (2011) Assessment of creep rupture properties for dissimilar steels welded joints between T92 and HR3C. Fatigue \& Fracture of Engineering Materials \& Structures 34(2): 83-96.

Goods SH and Brown LM (1979) Overview no. 1: The nucleation of cavities by plastic deformation. Acta Metallurgica 27(1): 1-15.

Hayhurst RJ, Mustata R and Hayhurst DR (2005) Creep constitutive equations for parent, type IV, R-HAZ, CG-HAZ and weld material in the range $565-640^{\circ} \mathrm{C}$ for $\mathrm{Cr}-\mathrm{Mo}-\mathrm{V}$ weldments. International Journal of Pressure Vessels \& Piping 82(2): 137-144.

Hongo H, Tabuchi M and Liu Y (2013) Microstructural changes and type-IV damage evolutions during creep in high Cr steel welds. Journal of the Japan Society for Testing Materials 62(2): 75-81.

Hyde TH, Becker AA and Sun W (2006) Finite-element creep damage analyses of P91 pipes. International Journal of Pressure Vessels \& Piping 83(11): 853-863.

Jablokov V, Goto DM and Koss DA (2001) Damage accumulation and failure of HY-100 steel. Metallurgical \& Materials Transactions A 32(12): 2985-2994.

Li Y, Hongo H, Tabuchi M, et al. (2009) Evaluation of creep damage in heat affected zone of thick welded joint for Mod.9Cr-1Mo steel. International Journal of Pressure Vessels \& Piping 86(9): 585-592.

Liu W, Liu X, Lu F, et al. (2015) Creep behavior and microstructure evaluation of welded joint in dissimilar modified 9Cr-1Mo steels. Materials Science \& Engineering A 644: 337-346.

Matsui M, Tabuchi M, Watanabe T, et al. (2001) Degradation of creep strength in welded joint of $9 \% \mathrm{Cr}$ steel. ISIJ International 41(Suppl)

Pandey VB, Singh IV, Mishra BK, et al. (2019) Creep crack simulations using continuum damage mechanics and extended finite element method. International Journal of Damage Mechanics 28(1): 3-34.

Perrin IJ and Hayhurst DR (1996) A method for the transformation of creep constitutive equations. International Journal of Pressure Vessels \& Piping 68(3): 299-309.

Shinozaki K and Kuroki H (2003) Stress-strain analysis of creep deterioration in heat affected weld zone in high Cr ferritic heat resistant steel. Metal Science Journal 19(9): 1253-1260.

Sun Y, Voyiadjis GZ, Hu W, et al. (2017) Fatigue and fretting fatigue life prediction of double-lap bolted joints using continuum damage mechanics-based approach. International Journal of Damage Mechanics 26(1): 162-188.

Van Zyl FH (2005) Life assessment and creep damage monitoring of high temperature and pressure components in South Africa's power plant. In: ECCC creep conference, London, pp.932-943 Voyiadjis GZ and

Kattan PI (2014) Healing and super healing in continuum damage mechanics. International Journal of Damage Mechanics 23(2): 245-260.

Wang X, Wang X, et al. (2017) Laves phase precipitation behavior in the simulated fine-grained heat-affected zone of creep strength enhanced ferritic steel P92 and its role in creep void nucleation and growth. Welding in the World 61(2): 231-239

Xiao Y (2004) A multi-mechanism damage coupling model. International Journal of Fatigue 26(11): 1241-1250.

Yao HT, Xuan FZ and Wang Z (2007) A review of creep analysis and design under multi-axial stress states. Nuclear Engineering \& Design 237(18): 1969-1986.

Zhao L, Jing H, Xu L, et al. (2012) Numerical investigation of factors affecting creep damage accumulation in ASME P92 steel welded joint. Materials \& Design 34: 566-575.

Życzkowski M (2000) Creep damage evolution equations expressed in terms of dissipated power. International Journal of Mechanical Sciences 42(4): 755-769. 